\title{
APPLICATIONS OF SECTIONS AND HALF VOLUMES IN STABILITY
}

\section{LUJUN GUO* AND XINJIE ZHANG}

Abstract. It is well known that one of the applications of spherical harmonics to convexity is to the so called uniqueness results, and also to stability results. In this paper, we consider sections and half volumes $V\left(K \cap u^{+}\right)$of star body $K$, where $u^{+}=\left\{x: x \in \mathbb{R}^{d}, x \cdot u \geqslant 0\right\}$. Using spherical harmonics, we show that the star bodies $K, L$ are identical if they have the same volumes of their central sections and half volumes and we also prove a stability version of this result.

Mathematics subject classification (2020): 52A20, 52A38, 33C55.

Keywords and phrases: Spherical harmonics, stability, convex bodies, half volumes, section.

\section{REFERENCES}

[1] YU. E. ANikONOV AND V. N. STEPANOV, An inversion formula in a problem of integral geometry, (Russian) Dokl. Akad. Nauk SSSR 318, no. 2 (1991), 265-266; translation in Soviet Math. Dokl. 43, no. 3 (1992), 678-679.

[2] K. BALL, Isometric problems in $l_{p}$ and sections of convex sets, Ph. D. dissertation, Trinity College, Cambridge (1986).

[3] K. BALL, Some remarks on the geometry of convex sets, in Geometric Aspects of Functional Analysis (J. Lindenstrauss and V. D. Milman, eds.), Lecture Notes in Math. 1317, Springer-Verlag, New York (1988), 224-231.

[4] K. J. BÖRÖCZKY AND R. SChNeIDER, Stable determination of convex bodies from sections, Studia Sci. Math. Hung. 46 (2009), 367-376.

[5] J. Bourgain, On high-dimensional maximal functions associated to convex bodies, Amer. J. Math., 108 (1986), 1467-1476.

[6] J. Bourgain, Geometry of Banach spaces and harmonic analysis, Proceedings of the International Congress of Mathematicians, Vol. 1, 2 (Berkeley, Calif., 1986), Amer. Math. Soc., Providence, RI, (1987), 871-878.

[7] J. Bourgain, On the Busemann-Petty problem for perturbations of the ball, Geom. Funct. Anal. 1 (1991), 1-13.

[8] H. Busemann and C. M. Petty, Problems on convex bodies, Math. Scand. 4 (1956), 88-94.

[9] R. J. GARDNER, A positive answer to the Busemann-Petty problem in three dimensions, Ann. of Math. 140 (1994) 435-447.

[10] R. J. GARDNER, Intersection bodies and the Busemann-Petty problem, Trans. Amer. Math. Soc. 342 (1994) 435-445.

[11] R. J. Gardner, Geometric Tomography, 2th edition, Encyclopedia of Mathematics and its Applications, vol. 58, Cambridge University Press, Cambridge, 2006.

[12] R. J. Gardner, A. Koldobsky AND T. SChlumprecht, An analytic solution to the BusemannPetty problem on sections of convex bodies, Ann. of Math., 149 (1999), 691-703.

[13] A. Giannopoulos, A note on a problem of H. Busemann and C. M. Petty concerning sections of symmetric convex bodies, Mathematika 37 (1990), 239-244.

[14] A. Giannopoulos And A. Koldobsky, Volum difference inequities, Trans. Amer. Math. Soc. 370 (2018), 4351-4372.

[15] P. Goodey And W. Weil, Average section functions for star-shaped sets, Adv. Math. 36 (2006), $70-84$.

[16] P. Goodey, V. Yaskin And M. Yaskina, Fourier transforms and the Funk-Hecke theorem in convex geometry, J. London Math. Soc. (2) 80 (2009), 388-404. 
[17] H. Groemer, Geometric Applications of Fourier Series and Spherical Harmonics, Cambridge University Press, New York, 1996.

[18] H. Groemer, On a spherical integral transform and sections of star bodies, Monatsh. Math. 126(1998), 117-124.

[19] L. Guo And G. Leng, Determination of star bodies from p-centroid bodies, Proc. Indian Acad. Sci. Math. Sci., 123 (2013), 577-586.

[20] L. Guo AND G. LenG, Stable determination of convex bodies from centroid bodies, Houston J. Math., 40 (2014), 395-406.

[21] A. KOLDOBSKY, An applications of the Fourier transform to sections of star bodies, Israel J. Math., 106 (1998), 157-164.

[22] D. G. LARMAN AND C. A. ROGERS, The existence of a centrally symmetric convex body with central sections that are unexpectedly small, Mathematika, 22 (1975), 164-175.

[23] E. LutwaK, Intersection bodies and dual mixed volumes, Adv. Math., 71 (1988), 232-261.

[24] V. D. Milman AND A. PAJOR, Isotropic position and inertia ellipsoids and zonoids of the unit ball of a normed $n$-dimensional space, Geometric aspects of functional analysis (1987-88), Lecture Notes in Math., vol. 1376, Springer, Berlin, 1989, 64-104.

[25] C. MÜLlER, Spherical Harmonics, Springer, Berlin/Heidelberg/New York, 1966.

[26] M. PAPADIMITRAKIS, On the Busemann-Petty problem about convex, centrally symmetric bodies in $\mathbb{R}^{n}$, Mathematika, 39 (1992), 258-266.

[27] R. SCHNEIDER, The use of spherical harmonics in convex geometry, http://home.mathematik. uni-freiburg.de/rschnei/Vortr\%E4ge.Kent.pdf.

[28] R. Schneider, Convex Bodies: The Brunn-Minkowski Theory, Encyclopedia Math. Appl., vol. 151, expanded edn. Cambridge University Press, Cambridge, 2014.

[29] V. N. STEPANOV, The method of spherical harmonics for integral transforms on a sphere, Mat. Strukt. Model. 42 (2017), 36-48.

[30] G. ZHANG, Intersection bodies and the Busemann-Petty inequalities in $\mathbb{R}^{4}$, Ann. of Math., 140 (1994), 331-346.

[31] G. ZHAng, A positive solution to the Busemann-Petty problem in $\mathbb{R}^{4}$, Ann. of Math., 149 (1999), $535-543$. 